\title{
A elaboração de um índice de segregação socioespacial como ferramenta de gestão e análise do espaço urbano de Viçosa, MG
}

\author{
The elaboration of a socio-spatial segregation index as a tool for the \\ management and analysis of the urban space of Viçosa, MG
La elaboración de un índice de segregación socioespacial como herramienta de gestión y análisis del espacio urbano de Viçosa, $M G$

\author{
Reinaldo Antônio Bastos Filho ${ }^{1}$ \\ Neide Maria de Almeida Pinto ${ }^{1}$ \\ Ana Louise de Carvalho Fiúza ${ }^{1}$ \\ Dimitri Fazito de Almeida Rezende 2
}

Recebido em 02/05/2018; revisado e aprovado em 20/11/2018; aceito em 29/11/2018

DOI: http://dx.doi.org/10.20435/inter.v20i3.1961

\begin{abstract}
Resumo: O presente trabalho objetivou analisar o espaço urbano da cidade de Viçosa, MG, a partir da elaboração de um índice de segregação socioespacial (ISSE). Utilizou-se, para tanto, uma pesquisa bibliográfica sobre o conceito de segregação socioespacial, para identificar as categorias e consequentemente os indicadores que o explicam e, em seguida, realizou-se uma pesquisa documental (dados secundários) sobre os indicadores selecionados, possibilitando a elaboração do ISSE. Como resultado da pesquisa, gráficos, tabelas e mapas foram elaborados, possibilitando assim, por meio dessas representações, uma análise e visualização clara da situação do fenômeno da segregação socioespacial no espaço urbano de Viçosa, MG. A pesquisa traz à luz a importância da elaboração desse índice como ferramenta de gestão e análise do espaço urbano, uma vez que revelou de forma objetiva o estado do fenômeno.
\end{abstract}

Palavras-chave: segregação socioespacial; desenvolvimento local; ferramenta de gestão; Viçosa, MG.

Abstract: The present work aimed to analyze the urban space of the city of Viçosa, MG, from the elaboration of a socio-spatial segregation index (ISSE). We used the bibliographical research on the concept of socio-spatial segregation to identify the indicators that explain it and then, a documentary research (secondary data) was carried out on the selected indicators enabling the elaboration of ISSE. As a result of the research, graphs, tables and maps were elaborated, thus making possible, through these representations, a clear analysis and visualization of the situation of the socio-spatial segregation phenomenon in the urban space of Viçosa, MG. The research brings to light the importance of the elaboration of this index as a management tool and analysis of the urban space, since it, objectively, revealed the state of the phenomenon.

Keywords: socio-spatial segregation; local development; management tool; city of Viçosa, MG.

Resumen: El presente trabajo objetivó analizar el espacio urbano de la ciudad de Viçosa, MG, a partir de la elaboración de un índice de segregación socioespacial (ISSE). Se utilizó la investigación bibliográfica sobre el concepto para identificar los indicadores que explican el mismo y luego se realizó una investigación documental (datos secundarios) sobre los indicadores seleccionados, posibilitando la elaboración del ISSE. Como resultado de la investigación, gráficos, tablas y mapas fueron elaborados, posibilitando así, por medio de esas representaciones, un análisis y visualización clara, de la situación del fenómeno de la segregación socioespacial en el espacio urbano de Viçosa, MG. La investigación vuelve a la luz la importancia de la elaboración de ese índice, como herramienta de gestión y análisis del espacio urbano, una vez que reveló de forma objetiva el estado del fenómeno.

Palabras clave: segregación socioespacial; desarrollo local; herramienta de gestión, Viçosa, MG

\footnotetext{
${ }^{1}$ Universidade Federal de Viçosa (UFV), Viçosa, Minas Gerais, Brasil.

${ }^{2}$ Universidade Federal de Minas Gerais (UFMG), Belo Horizonte, Minas Gerais, Brasil.
} 


\section{INTRODUÇÃO}

A partir da segunda metade do século XX, o processo de urbanização brasileira presenciou um crescimento muito rápido de suas cidades, "empurrando" e segregando socioespacialmente cada vez mais a classe trabalhadora para regiões periféricas, transformando seletivamente os espaços em termos de serviços e infraestrutura, configurando o espaço urbano como um local importante na luta de classe (GUIMARÃES, 2015; VILLAÇA, 2001). Dessa forma, essa "expulsão" e "disputa" pelas localidades no espaço urbano fez com que as diferentes classes ou camadas sociais se concentrassem em diferentes regiões gerais ou conjuntos de bairros, configurando o que Villaça (2001) chama de segregação.

Considerada uma característica marcante e um problema grave nas metrópoles brasileiras, a segregação espacial acaba criando regiões ou bairros muito particulares. De acordo com Ermínia Maricato (2000), a segregação socioespacial é a expressão maior da exclusão social e se configura em pontos de pobreza generalizada. Seu reconhecimento se dá na dificuldade de acesso a serviços e equipamentos coletivos, menores oportunidades de emprego e profissionalização, altos índices de violência, discriminação social contra mulheres e crianças etc.

Para Villaça (2001), o mais conhecido padrão de segregação brasileiro é o do centro x periferias. Ou seja, o centro, coberto por equipamentos urbanísticos, oportunidade de empregos, infraestrutura etc, ocupado principalmente pelas classes mais abastadas, e as periferias, localizadas longe do centro e desprovidas de serviços públicos e infraestrutura, ocupadas em sua maioria pela população de baixa renda.

Percebe-se que esses estudos, sobretudo, estão voltados para o entendimento do processo de segregação socioespacial nas grandes metrópoles brasileiras (VILLAÇA, 2001; CALDEIRA, 1997; 2000). Contudo esse processo também já é percebido em cidades menores do nosso território, o que torna necessário estudos voltados a esse perfil de cidade. Assim sendo, buscando entender como se configura a estrutura urbana da cidade, em termos de segregação socioespacial, esta pesquisa objetiva, através do conceito de Segregação Socioespacial e seus indicadores (definidos pelo conceito), elaborar um índice para medir o grau de Segregação Socioespacial na cidade de Viçosa, MG, considerada de porte médio $^{3}$ (BRASIL, 2005) por sua população total, que registra aproximadamente 76.147 mil habitantes (CRUZ, 2014).

\section{CARACTERIZAÇÃO DA CIDADE EM ESTUDO}

\subsection{A cidade de Viçosa, MG}

O município de Viçosa se localiza no estado de Minas Gerais, mais precisamente na Zona da Mata Mineira, e seu território ocupa uma área de aproximadamente $300 \mathrm{~km}^{2}$ (IBGE-CIDADES, 2015). É formado pela sede e por mais três distritos: Silvestre, Cachoeira de Santa Cruz e São José do Triunfo. Seu limite territorial faz fronteira com outros sete municípios, ao norte, com Teixeiras e Guaraciaba; Paula Cândido e Coimbra, ao sul; Cajuri e São Miguel do Anta, a leste; e Porto Firme, a oeste (Figura 1).

\footnotetext{
${ }^{3}$ Municípios de Pequeno Porte 1: até 20.000 habitantes, Município de Pequeno Porte 2: de 20.001 até 50.000 habitantes, Município de Médio Porte: de 50.001 até 100.000 habitantes, Município de Grande Porte: de 100.001 até 900.000 habitantes e Metrópole: Mais de 900.000 habitantes (BRASIL, 2005).
} 
Figura 1 - Limite territorial do Município de Viçosa, MG

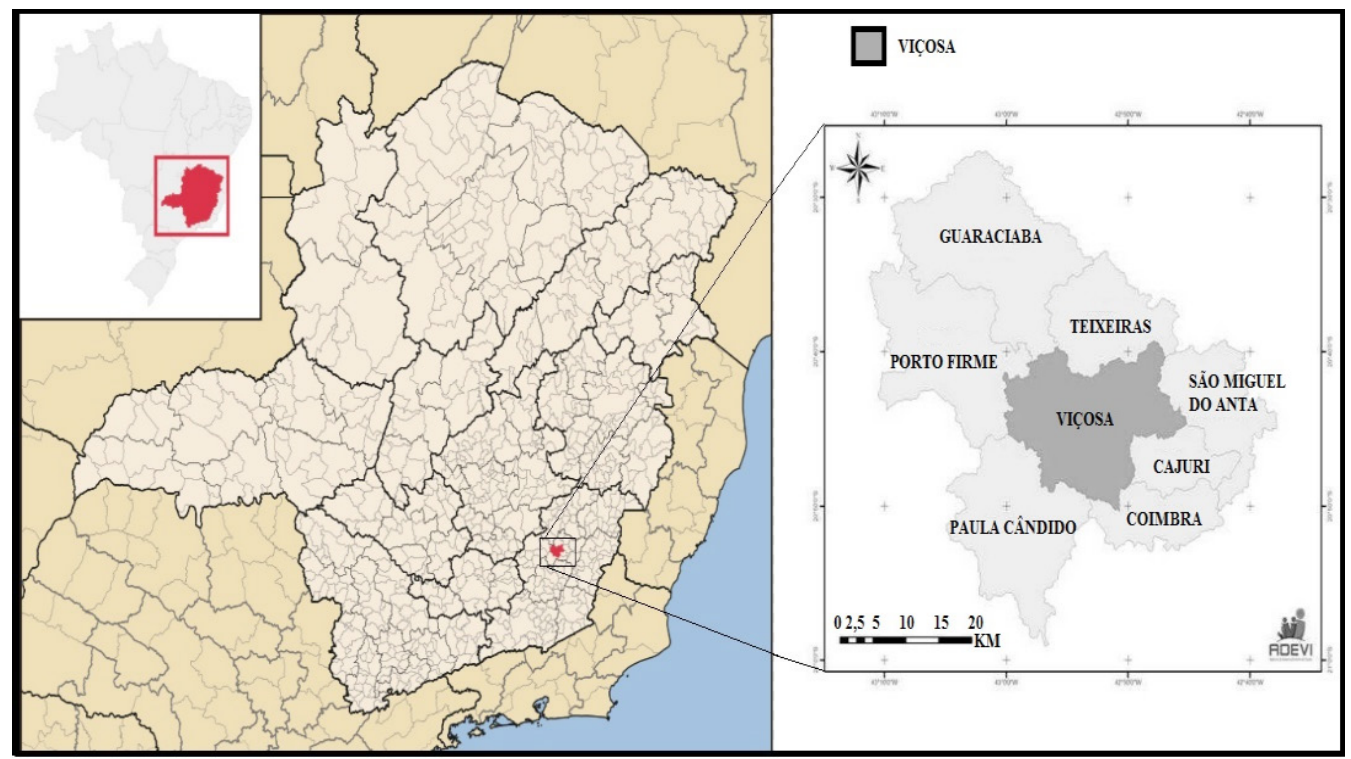

Fonte: Elaborado pelos autores (2017) com base em Cruz (2014).

A cidade, por sua vez, fica localizada no centro do território municipal (Figura 2), onde reside uma população urbana de 70.969 habitantes, o que representa 93,20\% da população (CRUZ, 2014) total do município (é uma das poucas cidades que, segundo o IBGE, 2015, possuem mais de 50 mil habitantes ${ }^{4}$.

Figura 2 - Região Urbana do Município de Viçosa, MG

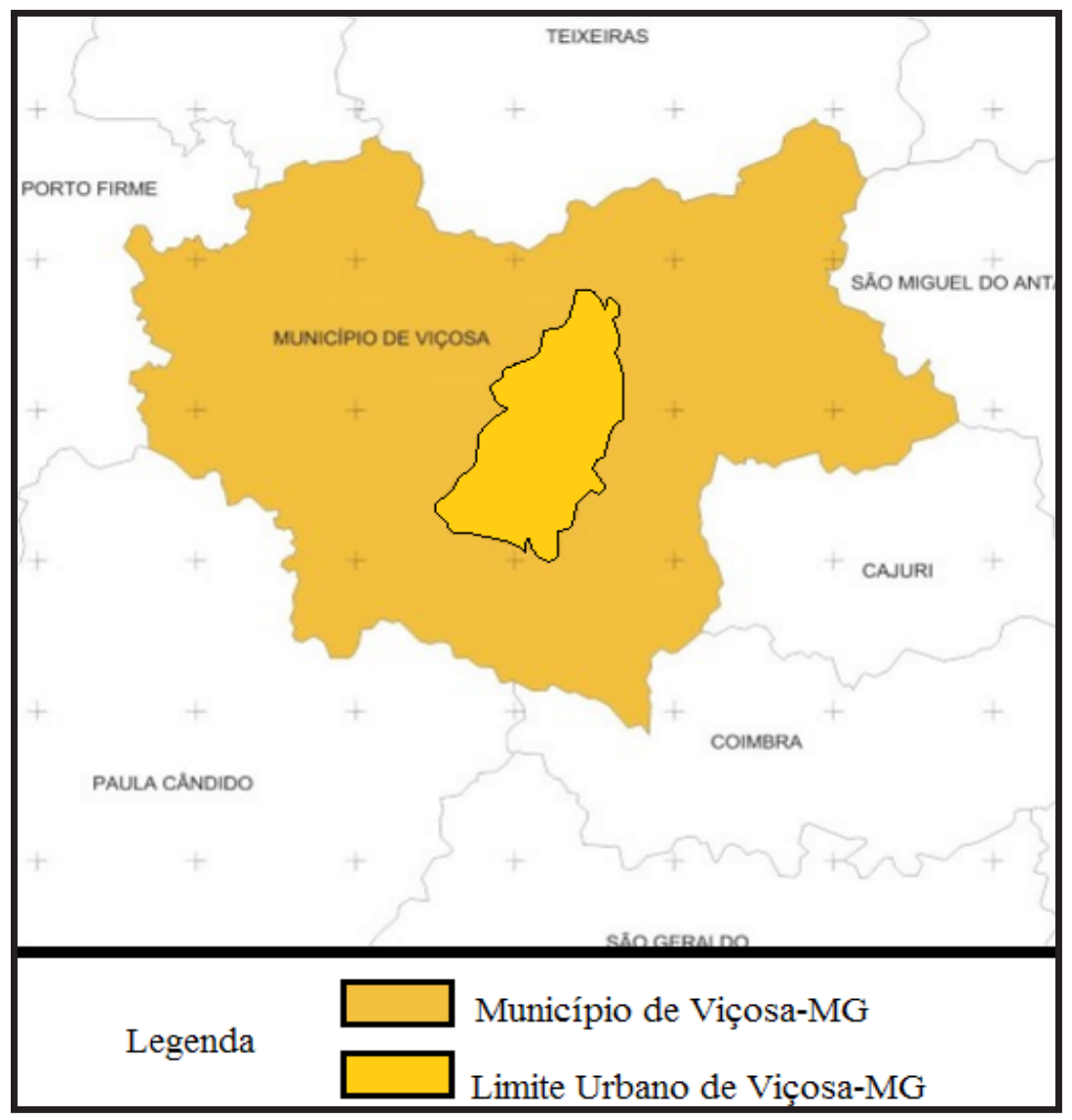

Fonte: Elaborado pelos autores com base em Cruz (2014).

\footnotetext{
${ }^{4}$ 11\% dos municípios brasileiros apresentam população maior do que 50 mil habitantes (IBGE, 2015).
} 
Segundo Cruz (2014), a cidade é dividida em 14 regiões urbanas de planejamento (Figura 3), entretanto, para esta pesquisa, como objeto de estudo, foram utilizadas as 12 regiões que fazem parte da unidade urbana. São elas: Centro ${ }^{5}$, Acamari $^{6}$, Bom Jesus $^{7}$, Nova Viçosa ${ }^{8}$, Fátima ${ }^{9}$, Lourdes $^{10}$, Santa Clara ${ }^{11}$, Passos ${ }^{12}$, Santo Antônio ${ }^{13}$, Nova Era ${ }^{14}$, Amoras ${ }^{15}$ e Silvestre ${ }^{16}$. As regiões Fundão e Cachoeirinha foram excluídas por serem distritos afastados da sede.

Figura 3 - Regiões Urbanas de Planejamento de Viçosa, MG

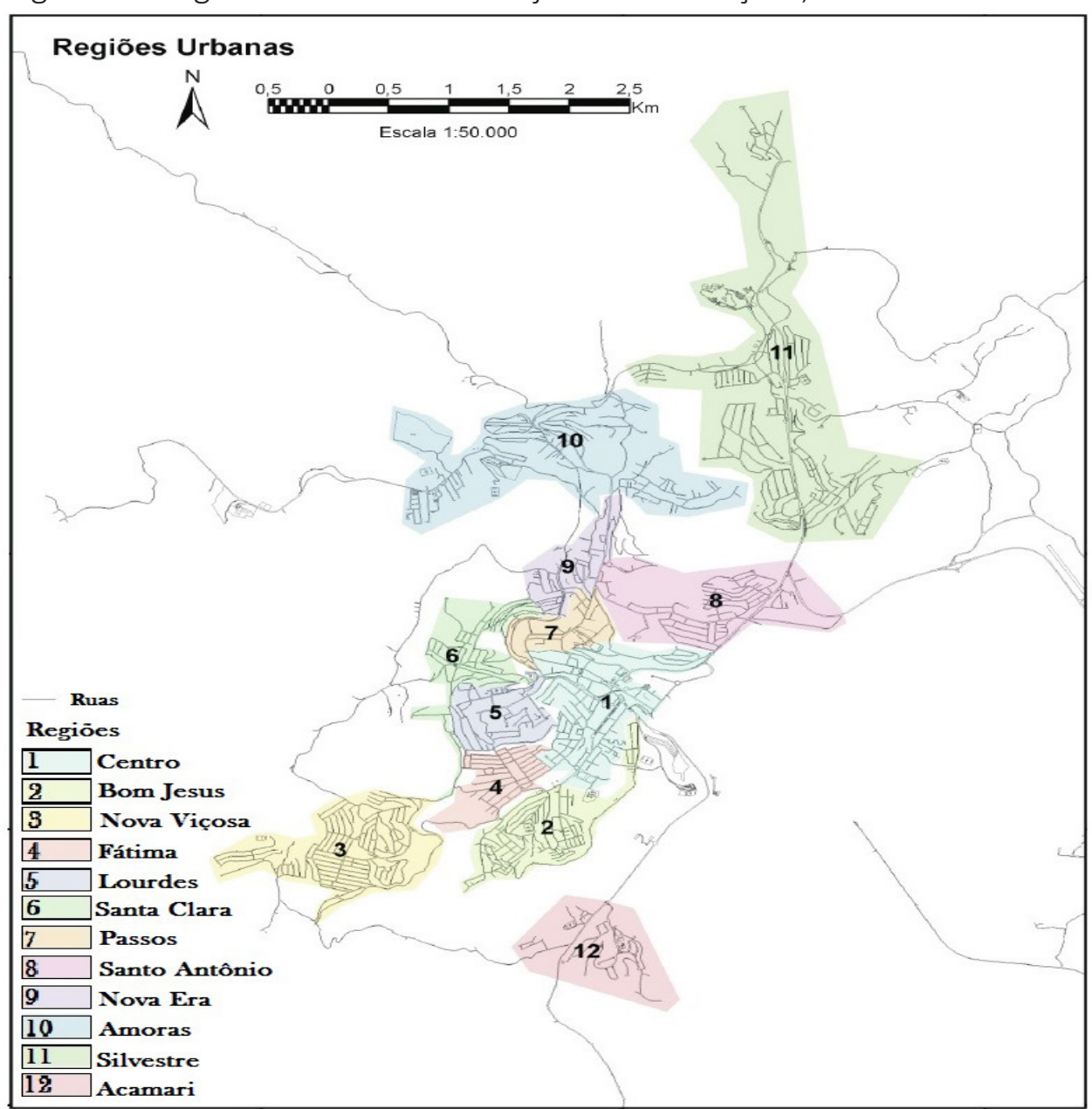

Fonte: Da Silva (2010).

\footnotetext{
${ }^{5}$ Ramos, Clélia Bernardes, Belvedere e Centro. Este último limitado pelas ruas: Gomes Barbosa, Ladeira dos Operários, José Antônio Rodrigues, Dos Estudantes, av. P. H. Rolfs (da linha férrea até a esquina com a Av. Castelo Branco), Av. Marechal Castelo Branco, (até o trevo do Belvedere), Geninho Lentine, Dr. Milton Bandeira, Dona Gertrudes, Tenente Kümmel, av. Bueno Brandão e Floriano Peixoto.

${ }^{6}$ Romão dos Reis, Rua Nova, Acamari, Vila Alves, Jardim do Vale, Quinta Dos Guimarães, Monte Verde e Otávio Pacheco.

${ }^{7}$ Bom Jesus, Bela Vista, Sagrada Família, Estrelas e Conceição.

${ }^{8}$ Nova Viçosa e Posses.

${ }^{9}$ Bairro de Fátima.

${ }^{10}$ Betânia, Santa Clara (parte baixa, limitada pela Av. JK até a Rua Joaquim Andrade), Lourdes e Al. Fábio Ribeiro Gomes.

11 JK, Santa Clara (parte alta), Maria Eugênia, Coelhas e São Sebastião.

${ }^{12}$ Fuad Chequer, Sagrado Coração (Rebenta Rabicho) e pela área limitada pela Rua dos Passos (do Hospital S.J. Batista até a esquina com a Dona Gertrudes), Rua Dr. Brito, Santana, Álvaro Gouveia e Dr. José N. Vaz de Melo.

${ }^{13}$ Julia Molar, Sto Antônio (do Belvedere até o trevo de Coimbra).

${ }^{14}$ Nova Era, Vale do Sol e União (Morro do Café).

${ }^{15}$ Barrinha, Cidade Nova, Arduino Bolívar (Amoras), Laranjal (São José), Boa Vista, Vau-Açú, Inácio Martins e Floresta.

${ }^{16}$ Liberdade, João Brás, Violeira, Recanto da Serra, Parque do Ipê, Inconfidentes, Silvestre e Novo Silvestre.
} 


\section{O CONCEITO DE SEGREGAÇÃO SOCIOESPACIAL}

O processo de segregação que acontece nas cidades é trabalhado por vários autores em diferentes visões, uma delas percebe esse processo como sendo uma manifestação da renda fundiária, no qual a classe de mais alta renda acaba ficando com as terras de mais alto valor e as pessoas de mais baixa renda, ao contrário, com as mais baratas (LOJKINE, 1981). Contudo essa corrente já foi refutada por vários trabalhos empíricos, um deles é o trabalho de Alonso (1965), referindo-se às cidades dos Estados Unidos da América. No Brasil, de acordo com Villaça (2001), nem sempre as camadas mais ricas ocupam as terras mais caras (de maior preço por metro quadrado), mesmo que isso ocorra na maioria das vezes. Não obstante, a classe de mais alta renda também ocupa terras baratas nas periferias de nossas cidades.

Segundo Villaça (2001), outros autores entendem esse processo de segregação como sendo fruto da pressão de poderes políticos e econômicos sobre o Estado, agenciando distribuição desigual dos investimentos em infraestrutura (VETTER; MASSENA, 1981; PINÇON-CHARLOT; PRETECEILLE; RENDU, 1986).

Uma terceira linha de pesquisa, na qual nos apoiaremos para embasar esta pesquisa, trabalha com a ideia de que o processo de segregação é resultado de uma luta ou disputa por localizações, a qual se dá, no entanto, entre grupos sociais ou entre classes (CASTELLS, 1983; VILLAÇA, 2001; 2011; MARICATO, 1997; 2000; LEFEBVRE, 2002; GUIMARÃES, 2015; BONDUKI, 1998; 2010). Dentro dessa perspectiva, algumas pesquisas datadas dos anos 1970 e início dos 1980 se voltaram para a questão das periferias - locais afastados do centro, habitados pela população trabalhadora, desprovidos tanto de serviços, quanto de equipamentos públicos marcados por condições sociais e urbanas muito precárias (BONDUKI; ROLNIK, 1982). Caldeira (2000), por sua vez, inclui alguns elementos como o crescimento dos crimes, o crescente medo da violência e as grandes transformações que vêm passando as cidades nas décadas 80 e 90, para explicar a produção de um novo padrão de segregação em São Paulo, os "Enclaves Fortificados".

Villaça (2001), seguindo essa corrente, complementa dizendo que a segregação é um processo no qual distintas classes ou camadas sociais tendem a se concentrar cada vez mais em diferentes regiões ou conjunto de bairros da metrópole. Assim, a localização da moradia (em relação ao centro) é um indicador importante, pois, segundo o autor, envolve o deslocamento de pessoas ou produtos entre locais de moradias e os de produção e consumo. Ou seja, a segregação como separação social (VILLAÇA, 2001; CALDEIRA, 2000). Do Lago (2002) e Maricato (1997; 2000; 2013), de maneira complementar, falam que a segregação, além de separação, também significa desigualdade de acesso.

Caldeira (2000) por sua vez, percebe a segregação socioespacial como uma característica importante das cidades. Ou seja, dentro dessa perspectiva, o espaço urbano é organizado por padrões de diferenciação social e de separação, essencialmente. Esses padrões variam cultural e historicamente, o que acaba por revelar os princípios estruturantes da vida pública, mostrando também como os grupos sociais se inter-relacionam no espaço da cidade. Para a autora (CALDEIRA, 2000), tomando o espaço urbano de São Paulo como exemplo, durante o século XX, a segregação social teve no mínimo três diferentes expressões:

A primeira estendeu-se do final do século XIX até os anos 1940 e produziu uma cidade concentrada em que os diferentes grupos sociais se comprimiam numa área urbana pequena e estavam segregados por tipos de moradia. A segunda forma urbana, a centro-periferia, dominou o desenvolvimento da cidade dos anos 40 até os anos 80 . Nela, diferentes grupos 
sociais estão separados por grandes distâncias: as classes média e alta concentram-se nos bairros centrais com boa infraestrutura, e os pobres vivem nas precárias e distantes periferias. Embora os moradores e cientistas sociais ainda concebam e discutam a cidade em termos do segundo padrão, uma terceira forma vem se configurando desde os anos 80 e mudando consideravelmente a cidade e sua região metropolitana. Sobrepostas ao padrão centro-periferia, as transformações recentes estão gerando espaços nos quais os diferentes grupos sociais estão muitas vezes próximos, mas estão separados por muros e tecnologias de segurança, e tendem a não circular ou interagir em áreas comuns. O principal instrumento desse novo padrão de segregação espacial é o que chamo de "enclaves fortificados ${ }^{17}$ ". (CALDEIRA, 2000, p. 211).

Para Sposito (2016), a segregação acontece quando as formas de diferenciação causam uma separação espacial radical e implicam quebra, sempre relativa, da região segregada e o conjunto do espaço urbano, gerando consequentemente uma dificuldade nas relações e nas articulações que movem a vida na cidade.

No Brasil, o mais conhecido padrão de segregação é o segundo citado por Caldeira (2000), centro versus periferia, em que o centro apresenta acesso a serviços urbanos, seja público ou privado, ocupado pelas camadas de mais alta renda, e a periferia, ao contrário, subequipada e longínqua, ocupada pelas camadas de mais baixa renda (VILLAÇA, 2001) acabando por criar uma dualidade entre cidade dos ricos e cidade dos pobres, ou mesmo entre cidade legal e cidade ilegal (BONDUKI, 2010). Ou seja, dessa maneira, a segregação socioespacial se tornou uma marca forte na consolidação das periferias, em comparação às melhores e maiores condições das camadas altas e médias da sociedade nas disputas por prioridades estatais e por recursos públicos, e essa ausência nas periferias foi contínua na urbanização periférica, isto é, desenvolveu-se uma estrutura precária, com insuficientes equipamentos sociais, déficit de infraestrutura e melhorias urbanas essenciais, resultado da ocupação desordenada e ilegal, que acaba por comprometer a qualidade de vida, a mobilidade, acesso a serviços e também ao mercado de trabalho (HUGHES, 2004).

Tabela 1 - Síntese conceitual

\begin{tabular}{|c|c|c|}
\hline \multicolumn{3}{|c|}{ Síntese conceitual (Segregação Socioespacial) } \\
\hline $\begin{array}{l}\text { Características de locais } \\
\text { segregados socioespacialmente }\end{array}$ & Categorias & Padrão de Segregação Socioespacial \\
\hline Locais afastados do centro & Separação Espacial & \multirow{4}{*}{$\begin{array}{l}\text { - Centro versus Periferia } \\
\text { - Cidade de ricos versus cidade dos } \\
\text { pobres } \\
\text { - Cidade legal versus cidade ilegal }\end{array}$} \\
\hline $\begin{array}{l}\text { Locais habitados por população da } \\
\text { classe trabalhadora e marcados por } \\
\text { condições sociais precárias }\end{array}$ & Separação Social & \\
\hline $\begin{array}{l}\text { Locais desprovidos tanto de } \\
\text { serviços quanto de equipamentos } \\
\text { públicos }\end{array}$ & \multirow{2}{*}{$\begin{array}{l}\text { Desigualdade de } \\
\text { acesso }\end{array}$} & \\
\hline $\begin{array}{l}\text { Locais marcados por condições } \\
\text { urbanas muito precárias }\end{array}$ & & \\
\hline
\end{tabular}

Fonte: Elaboração própria com base nos autores descritos no tópico 2, (2019).

\footnotetext{
${ }^{17}$ Espaços privatizados, fechados e monitorados, constituem o principal instrumento desse novo padrão de segregação, justificado pelo medo do crime e da violência por parte daqueles que se sentem ameaçados e preferem abandonar os espaços de livre acesso e circulação, característicos da vida urbana e do espaço público modernos (CALDEIRA, 2000, p. 211).
} 


\section{PROCEDIMENTOS METODOLÓGICOS}

Com intuito de facilitar a compreensão da segregação socioespacial que existe na cidade de Viçosa, MG, este trabalho utilizou-se de pesquisa Bibliográfica para entendimento do conceito em questão e da pesquisa documental para elaboração de um índice que contemplasse o máximo de indicadores (disponíveis em bancos de dados secundários) que representassem o conceito de Segregação Socioespacial. Para tanto, em primeiro lugar, torna-se importante definir o que é um índice, antes de expor-Ihe as etapas de elaboração. Segundo Observatório Regional Base de Indicadores de Sustentabilidade (ORBIS, 2010, p. 11):

O índice (ou indicador sintético) é a combinação de diversas variáveis que sintetizam um conceito abstrato complexo, em um único valor, para facilitar a comparação entre localidades e grupos distintos, possibilitando a criação de rankings e pontos de corte para apoiar a definição de, por exemplo, políticas, investimentos e ações comuns.

Habitualmente, tanto os índices, quanto os indicadores, são utilizados para possibilitar o entendimento e a comparação de determinado fenômeno social ao longo do tempo e em diferentes espaços geográficos (ORBIS, 2010). Assim sendo, existem alguns índices para medir a segregação, como é o caso do índice de dissimilaridade e o índice de Moran global, contudo apresentam limitações sobre o conceito de segregação socioespacial. O primeiro, a despeito de ser popular, apresenta deficiência quanto ao seu caráter não espacial. O segundo, por sua vez, tem o caráter espacial. Ou seja, mede a semelhança entre uma dada área e seus vizinhos, porém relacionado a uma determinada variável, como pobreza ou raça, por exemplo (ANSELIN, 1995). Dessa forma, buscando relacionar o máximo de variáveis que respondam ao conceito estudado, optou-se pelo desenvolvimento de um índice que representasse a realidade da segregação socioespacial da cidade de Viçosa, MG. Visto isso, para a elaboração do índice, fez-se necessário o cumprimento de 4 etapas, são elas: seleção de indicadores/Variáveis, criação de uma planilha Excel com os indicadores, definição de pesos e pontuações das variáveis e, por fim, a redução dos valores em um índice.

A primeira etapa foi a seleção dos indicadores ${ }^{18}$ que representam o indicador Sintético (índice), são elas: distância em relação ao centro, déficit habitacional, dados socioeconômicos, Infraestrutura, educação, acessibilidade, vulnerabilidade ${ }^{19}$ familiar, violência, saúde e taxa de emprego.

\footnotetext{
${ }^{18}$ Utilizou-se aqueles indicadores acessíveis, seja por documentos ou por sites das instituições.

${ }^{19}$ Critérios de Enquadramento na Condição de Família em Situação de Vulnerabilidade Social segundo Norma Operacional Básica do Sistema Único de Assistência Social - NOB / SUAS - MDS. Considera-se como população vulnerável o conjunto de pessoas residentes que apresentam pelo menos uma das características abaixo: 1- Famílias que residem em domicílio com serviços de infraestrutura inadequados. Conforme definição do IBGE, trata-se dos domicílios particulares permanentes com abastecimento de água proveniente de poço ou nascente ou outra forma, sem banheiro e sanitário ou com escoadouro ligado à fossa rudimentar, vala, rio, lago, mar ou outra forma e lixo queimado, enterrado ou jogado em terreno baldio ou logradouro, em rio, lago ou mar ou outro e mais de dois moradores por dormitório. 2- Famílias com renda familiar per capita inferior a um quarto de salário mínimo. 3- Famílias com renda familiar per capita inferior a meio salário mínimo cujo responsável tenha menos de quatro anos de estudo e com pessoas de 0 a 14 anos. 4- Família na qual o responsável é mulher, analfabeta, sem cônjuge, com filhos menores de 15 anos. 5- Família na qual há uma pessoa com 16 anos ou mais, desocupada (procurando emprego) com quatro ou menos anos de estudo. 6- Família na qual há uma pessoa com 10 a 15 anos de idade e que trabalhe. 7- Família na qual há uma pessoa com 4 a 14 anos de idade que não estude. 8- Família com renda familiar per capita inferior a meio salário mínimo, com pessoas de 60 anos ou mais. 9- Família com renda familiar per capita inferior a meio salário mínimo, com uma pessoa com deficiência.
} 
Tabela 2 - Síntese de variáveis, indicadores utilizados e fonte

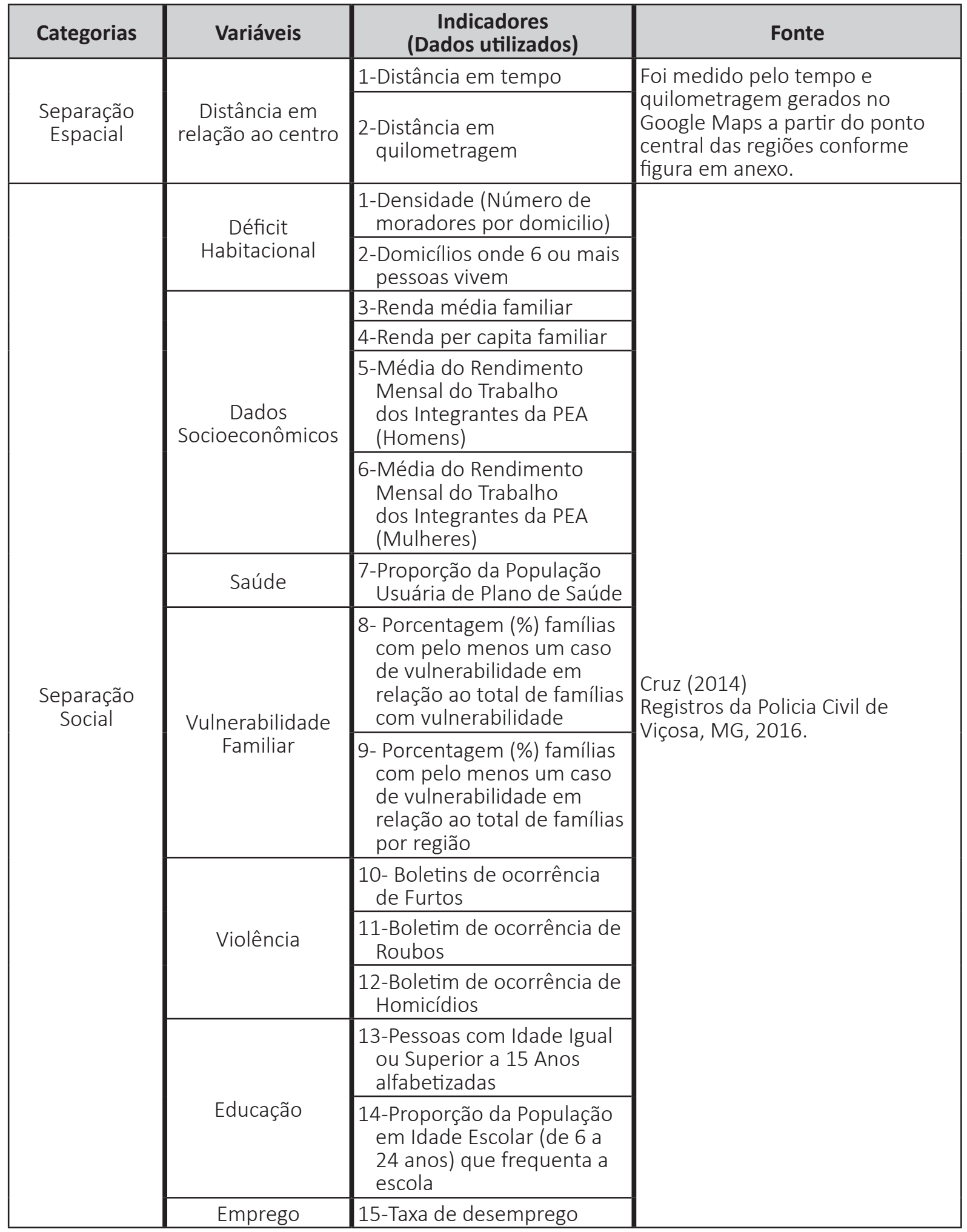




\begin{tabular}{|c|c|c|c|}
\hline Categorias & Variáveis & $\begin{array}{c}\text { Indicadores } \\
\text { (Dados utilizados) }\end{array}$ & Fonte \\
\hline \multirow{10}{*}{$\begin{array}{l}\text { Desigualdades } \\
\text { de Acessos }\end{array}$} & \multirow{6}{*}{ Educação } & $\begin{array}{l}\text { 1-Número de Pré-escolar } \\
\text { (municipal) }\end{array}$ & \multirow{6}{*}{$\begin{array}{l}\text { Plano Diretor de Viçosa/ } \\
\text { Escolas. Disponível em: } \\
\text { http://www.ufv.br/pdv/ } \\
\text { EscolasMunicipaiseEstaduais.htm } \\
\text { e http://www.escolas.inf.br/mg/ } \\
\text { vicosa. Acesso em: } 3 \text { mar. } 2017\end{array}$} \\
\hline & & $\begin{array}{l}\text { 2-Número de Escolas de } \\
\text { 1a a a } 4 \text { a série (municipal e } \\
\text { Estadual) } \\
\end{array}$ & \\
\hline & & $\begin{array}{l}\text { 3-Número de Escolas de } \\
\text { 5a a 8a série (municipal e } \\
\text { Estadual) }\end{array}$ & \\
\hline & & $\begin{array}{l}\text { 4-Número de Escolas } \\
\text { Supletivo }\end{array}$ & \\
\hline & & $\begin{array}{l}\text { 5-Número de Escolas de 2o } \\
\text { grau (Municipal, Estadual e } \\
\text { Federal) }\end{array}$ & \\
\hline & & $\begin{array}{l}\text { 6-Número de Escolas } \\
\text { Particulares }\end{array}$ & \\
\hline & \multirow[b]{2}{*}{ Acessibilidade } & $\begin{array}{l}\text { 7-Linhas de ônibus presentes } \\
\text { no bairro }\end{array}$ & \multirow{2}{*}{$\begin{array}{l}\text { http://www.viacaouniao.com. } \\
\text { br/images/horarios-vicosa.pdf, } \\
\text { http://www.viacaouniao.com. } \\
\text { br/images/trajetos.pdf e http:// } \\
\text { www.viacaouniao.com.br/. } \\
\text { Acesso em: } 3 \text { mar. } 2017 .\end{array}$} \\
\hline & & $\begin{array}{l}\text { 8-Número de dias por } \\
\text { semana em que há esse } \\
\text { serviço. }\end{array}$ & \\
\hline & Infraestrutura & $\begin{array}{l}\text { 9-Número de dias da } \\
\text { semana em que há Coleta } \\
\text { de lixo }\end{array}$ & Cruz (2014) \\
\hline & Saúde & $\begin{array}{l}\text { 10-Número de programa } \\
\text { saúde da família (PSF) e } \\
\text { Hospitais por Região }\end{array}$ & $\begin{array}{l}\text { Cruz (2014) } \\
\text { https://blogsaudevicosa. } \\
\text { wordpress.com/programa-de- } \\
\text { saude-da-familia-2/ e http:// } \\
\text { www.vicosa.mg.gov.br/detalhe- } \\
\text { da-materia/info/secretaria- } \\
\text { municipal-de-saude/11027 } \\
\text { Acesso em: } 07 \text { ago. } 2019 \\
\end{array}$ \\
\hline
\end{tabular}

Fonte: Elaboração própria com base em dados da pesquisa (2017).

Após a definição dos 27 indicadores que compõem o conceito, utilizou-se a ferramenta Excel para desenvolvimento de uma planilha com as respectivas informações para cada região (as regiões urbanas de planejamento foram agrupadas nas linhas e seus respectivos indicadores nas colunas). Em seguida, optou-se por atribuir pesos iguais (33,33\%) a cada uma das três categorias (Separação espacial, separação social e desigualdade de acessos descritos na tabela 1), uma vez que todos contribuem da mesma forma para a caracterização da segregação socioespacial, de acordo com os autores supracitados.

Quanto às pontuações referentes a cada indicador, optou-se pela categorização em quatro grupos (Cluster), de acordo com a média e o desvio-padrão para cada indicador, ou seja, aqueles valores do indicador abaixo de menos um desvio, foram atribuídos 1 (um), para os valores entre a média e menos um desvio será atribuído 0,750, os valores até um desvio atribuiu-se 0,250, e por fim, acima de um desvio atribuiu-se 0,0 (zero), e isso foi repetido para cada um dos 25 indicadores numéricos.

Os outros dois indicadores que compõem os 27 são nominais, ou seja, apresentavam como resposta, "sim" ou "não". Para transformá-los em numéricos, àqueles indicadores que apresen- 
taram o "sim" como resposta, apresentando acesso ao serviço público, foi atribuído 0 (Zero) e para aqueles que apresentaram o "não", sem acesso ao serviço, foi atribuído 1 (um). Após realizar essas pontuações, somaram-se todos os valores para cada região por categoria, ou seja, para a região centro, por exemplo, somou-se o indicador 1 ao indicador 2 , que compõem a categoria separação espacial; indicador 1 , indicador 2 até o indicador 15, para a categoria separação social; e indicador 1, indicador 2 até indicador 10, para categoria desigualdade de acessos, gerando assim um valor entre 0 e 2 para a primeira categoria, 0 a 15 para a segunda e 0 a 10 para a terceira categoria, que posteriormente foram reduzidos, proporcionalmente ao valor de 33,333\%, referente ao peso atribuído a cada uma das três categoria, conforme exemplo da tabela 3.

Tabela 3 - Procedimento de construção da soma dos indicadores por categoria

\begin{tabular}{|c|c|c|c|c|c|c|c|c|}
\hline \multicolumn{8}{|c|}{ Separação Social (SS) - 33,333\% } \\
\hline $\begin{array}{c}\text { Regiões } \\
\text { Urbanas }\end{array}$ & $\begin{array}{c}\text { Soma dos } \\
\text { Indicadores }\end{array}$ & $\mathrm{I}-1$ & $\mathrm{I}-2$ & $\mathrm{I}-3$ & $\mathrm{I}-4$ & $\mathrm{I}-5$ & $\ldots$ & $\mathrm{I}-15$ \\
\hline Centro & 2,750 & 0 & 0 & 0,25 & 0 & 0 & $\ldots$ & 0 \\
\hline Acamari & 2,250 & 0 & 0 & 0,25 & 0,75 & 0,25 & $\ldots$ & 0,25 \\
\hline$\ldots$ & $\ldots$ & $\ldots$ & $\ldots$ & $\ldots$ & $\ldots$ & $\ldots$ & $\ldots$ & $\ldots$ \\
\hline Santa Clara & 11,000 & 0,75 & 0,75 & 0,75 & 1 & 1 & $\ldots$ & 0,75 \\
\hline Nova Viçosa & 11,500 & 1 & 1 & 0 & 1 & 1 & $\ldots$ & 1 \\
\hline
\end{tabular}

Fonte: elaboração própria com base em dados da pesquisa (2018).

Em outras palavras, a "soma dos indicadores" representa o somatório dos 15 indicadores para a categoria separação social em cada região urbana de planejamento (tabela 2). Isso se repetiu para as outras duas categorias, separação espacial, com seus dois indicadores, e desigualdade de acessos, com 10 indicadores, conforme tabela 4 abaixo.

Tabela 4 - Exemplo do procedimento de construção do índice de Segregação Socioespacial

\begin{tabular}{|c|c|c|c|c|}
\hline \multirow{2}{*}{$\begin{array}{c}\text { Região } \\
\text { Urbana }\end{array}$} & ISSE & $\begin{array}{c}\text { Separação Espacial (SE) } \\
\mathbf{2} \text { indicadores } \\
\mathbf{3 3 , 3 3 3 \%}\end{array}$ & $\begin{array}{c}\text { Separação Social (SS) } \\
\mathbf{1 5} \text { indicadores } \\
\mathbf{3 3 , 3 3 3 \%}\end{array}$ & $\begin{array}{c}\text { Desigualdade de } \\
\text { acessos (DA) } \\
\mathbf{1 0} \text { indicadores } \\
\mathbf{3 3 , 3 3 3 \%}\end{array}$ \\
\hline Centro & 0,078 & 0,000 & 2,750 & 0,500 \\
\hline Acamari & 0,417 & 1,000 & 2,250 & 6,000 \\
\hline Santa Clara & 0,636 & $\ldots$ & $\ldots$ & $\ldots$ \\
\hline Nova Viçosa & 0,681 & 1,500 & 11,000 & 4,250 \\
\hline
\end{tabular}

Fonte: elaboração própria com base em dados da pesquisa (2018).

Após essa soma de indicadores, para cada categoria em cada região urbana, converteu-se o valor do índice (ISSE) em um número entre 0 e 1 (ISSE, Tabela 4), utilizando-se a seguinte fórmula:

$$
I(\text { Região })=\left\{\left[\left(\frac{\sum_{K=1}^{n_{S E} I_{S E}(i)}}{n_{S E}}\right) \times \frac{1}{3}\right]+\left[\left(\frac{\sum_{K=1}^{n_{S S} I_{S S}(i)}}{n_{S S}}\right) \times \frac{1}{3}\right]+\left[\left(\frac{\sum_{K=1}^{n_{D A} I_{D A}(i)}}{n_{D A}}\right) \times \frac{1}{3}\right]\right\}
$$




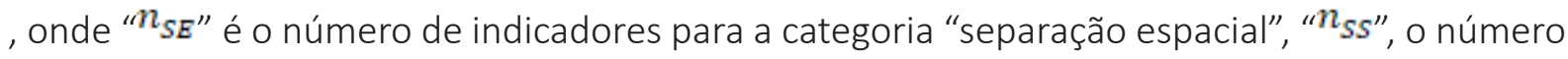
de indicadores para a categoria "separação social"; e "n $n_{D A}$ ", o número de indicadores para a categoria "desigualdade de acessos", referentes a cada região urbana de planejamento, I(Região). Em outras palavras, esse cálculo foi repetido para cada uma das 12 regiões urbanas de planejamento, gerando o índice utilizado nas discussões deste trabalho.

\section{RESULTADOS E DISCUSSÕES}

Após aplicação da fórmula no somátorio dos indicadores, foi criado uma tabela que representa os valores de cada uma das regiões urbanas de planejamento estudada. Os valores mínimos e máximos variam de 0,078 (região de planejamento sem segregação socioespacial- Centro) até 0,681 (Região mais segregada Socioespacialmente - Nova Viçosa) conforme descrição da tabela 5 abaixo.

Tabela 5 - Índice de Segregação Socioespacial de Viçosa, MG

\begin{tabular}{|c|c|}
\hline REGIÕES & $\begin{array}{c}\text { Índice }{ }^{20} \text { de Segregação Socioespacial no Município de } \\
\text { Viçosa por região urbana de Planejamento (ISSE) }\end{array}$ \\
\hline 1. Centro ${ }^{21}$ & 0,078 \\
\hline 2. Fátima & 0,311 \\
\hline 3. Lourdes & 0,311 \\
\hline 4. Santo Antônio & 0,378 \\
\hline 5. Acamari & 0,417 \\
\hline 6. Bom Jesus & 0,442 \\
\hline 7. Nova Era & 0,450 \\
\hline 8. Passos & 0,456 \\
\hline 9. Silvestre & 0,456 \\
\hline 10. Amoras & 0,556 \\
\hline 11. Santa Clara & 0,636 \\
\hline 12. Nova Viçosa & 0,681 \\
\hline
\end{tabular}

Fonte: Elaboração própria (2018) com base em dados de Cruz (2014), Viação União (2016), Google Maps (2017), Plano Diretor de Viçosa (S.d), Blog Saúde Viçosa (S.d) e Portal da Saúde- PMV (S.d).

Conforme os resultados apresentados, percebe-se que as Regiões Urbanas de Planejamento Santa Clara $(0,636)$ e Nova Viçosa $(0,681)$ foram aquelas que apresentaram os piores índices de Segregação Socioespacial, e isso é explicado quando analisamos mais aprofundadamente os seus indicadores, ou seja, são localidades onde as rendas média e per capita familiáres são mais baixas, acesso a escolas, hospitais e PSF's muito precário e reduzido em relação às demais, a vulnerabilidade familiar é muito elevada e, além disso, são afastadas do centro, indo ao encontro dos argumentos de vários autores (BONDUKI; ROLNIK, 1982; MARICATO, 1997; CALDEIRA, 2000; LEFEBVRE, 2002; VILLAÇA, 2001).

\footnotetext{
${ }^{20} \mathrm{O}$ índice varia de 0,0 a 1,0 sendo que, quanto mais próximo de 1,0, mais segregada socioespacialmente é a região urbana de planejamento.

${ }^{21}$ A região de Planejamento Centro se encontra com 0,078 (zero) por dois fatores: Ser a referência central e comercial da cidade e por abarcar quase todos os indicadores na faixa ideal.
} 
Figura 4 - Mapa representativo das duas Regiões Urbanas com os piores indicadores de segregação socioespacial

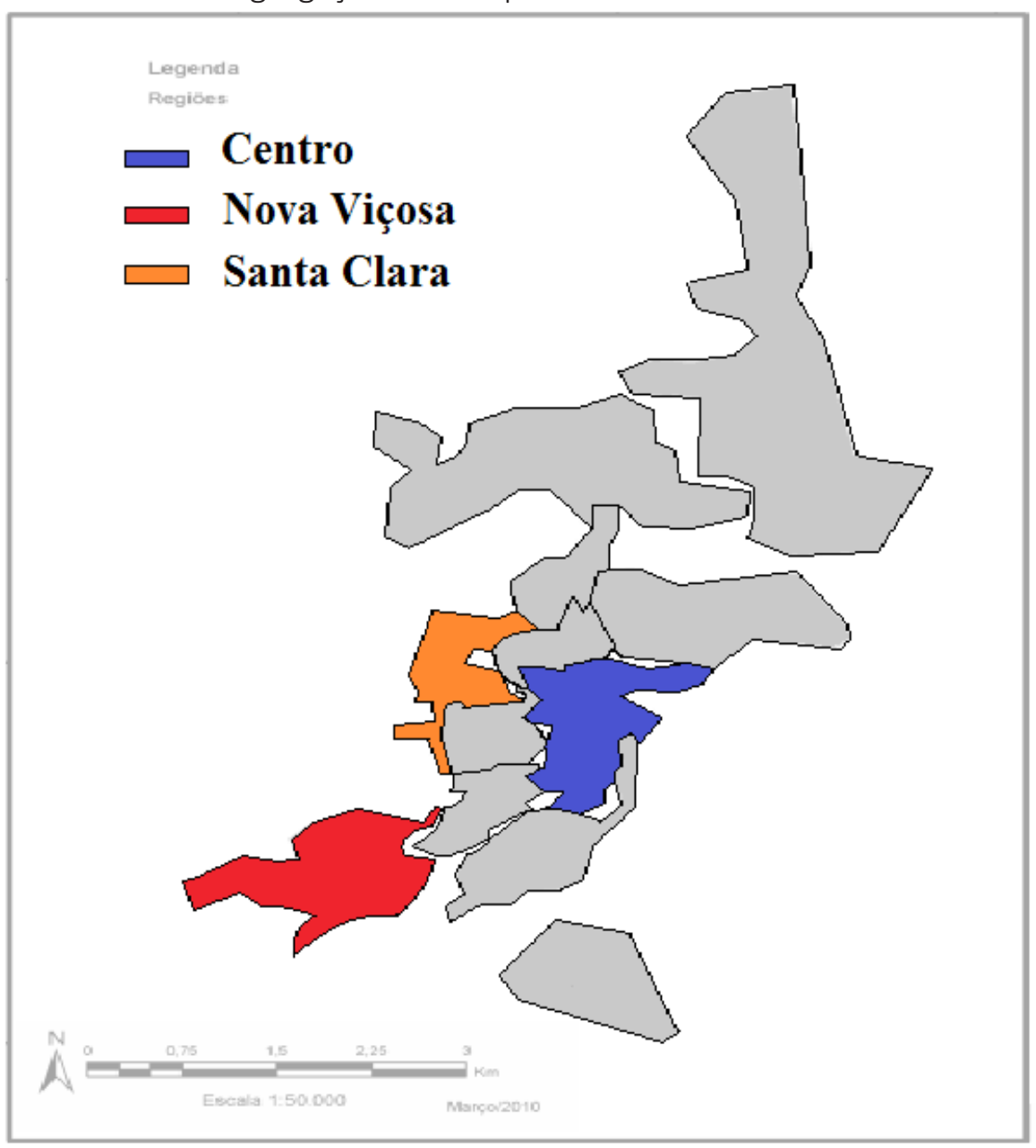

Fonte: Elaboração própria, com base em mapa de Cruz (2014) e dados da pesquisa (2017).

Com o índice pronto, foi realizado uma categorização em quatro grupos distintos de acordo com seus valores, são eles: Não segregado Socioespacilmente (em cor verde na Figura 5), baixa Segregação Socioespacial (Cor branca), média Segregação Socioespacial (Cor amarela) e alta Segregação Socioespacial (Cor Vermelha). 
Figura 5 - Representação gráfica do Índice de Segregação Socioespacial de Viçosa, MG

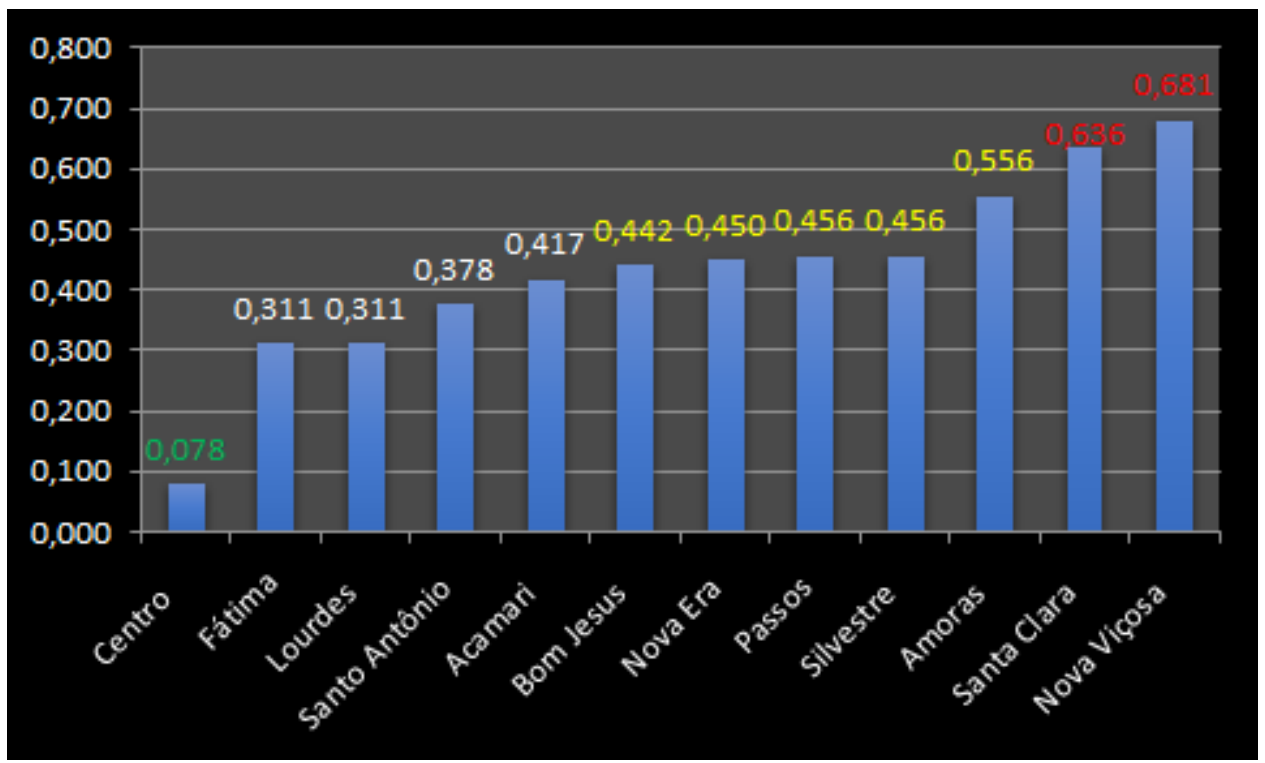

Fonte: Elaboração própria (2017)

Para tanto, realizou-se a média do índice $(0,430)$ e, posteriormente, o cálculo do DesvioPadrão (0,152); assim, aquelas regiões que apresentaram valores entre a média mais um desvio-padrão foram categorizadas como média Segregação Socioespacial (Bom Jesus, Nova Era, Passos, Silvestre e Amoras), acima dos valores da média mais um desvio, estão agrupadas as duas regiões caracterizadas como alta segregação, Região Nova Viçosa e Santa Clara, conforme descrisão anterior. Ao oposto das duas regiões mais segregadas socioespacialmente, percebe-se a região Centro, a única caracterizada como não segregada, uma vez que possui vários equipamentos urbanísticos como: escolas, proximidade com a Universidade Federal de Viçosa (UFV), delegacias, comércio e hospitais; além de alta renda média familiar, baixos índices de vulnerabilidade, fácil acesso às áreas de consumo, além da ótima localização.

Por fim, no grupo denominado baixa Segregação Socioespacial, estão agrupadas as regiões urbanas Fátima, Lourdes, Santo Antônio e Acamari, as quais apresentaram indicadores entre a média até menos um desvio. A região Acamari, apesar de aparecer nesse grupo, é uma região urbana que apresenta uma peculiaridade frente às demais, uma vez que um de seus bairros é um condomínio fechado, de luxo, denomidado por Caldeira (2000) como "enclave fortificado" ou, na visão de Corrêa (1989), como autossegregação. Ou seja, apesar de apresentar (Acamari) um índice de segregação de 0,417, e uma distância maior em relação ao centro, seus indicadores de renda média familiar, renda per capita familiar, média de rendimento mensal e pessoas com idade igual ou superior a 15 anos alfabetizadas são os mais elevados dentre todas as regiões urbana de planejamento da cidade. 
Figura 6 - Mapa da cidade de Viçosa, MG, com sobreposição do Índice de Segregação Socioespacial de Viçosa, MG

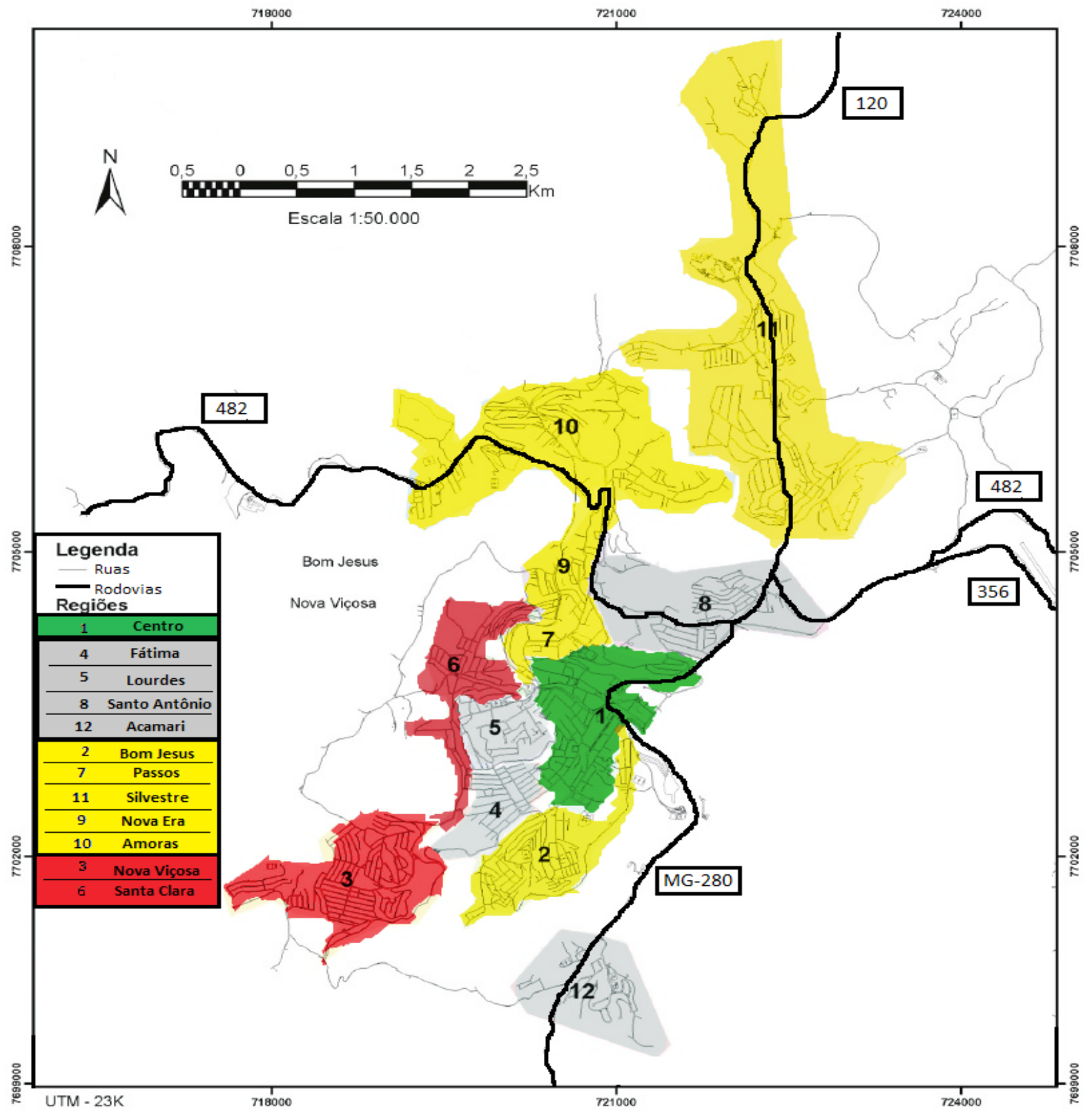

Fonte: Elaboração própria, com base em dados de Cruz (2014) e da pesquisa de campo (2017).

Em síntese, o que aconteceu na Região Acamari não é considerado uma segregação por imposição, pelo contrário, são seus moradores quem escolheram se fechar entre muros e se afastarem dos demais como uma forma de proteção e separação social, o que não aconteceu da mesma forma nas duas regiões mais pobres, onde a primeira, região Nova Viçosa, foi criada por uma construtora nos anos 70, com preços muito acessíveis à população de baixa renda que chegava à cidade em busca de novas oportunidades de emprego (COELHO, 2013). E a segunda, a região de Santa Clara, onde há um empreendimento do Programa Minha Casa Minha Vida, que foram entregues à população de baixa renda em setembro de 2011 e julho de 2012 (SOUZA, 2015). 


\section{CONSIDERAÇÕES FINAIS}

Em linhas gerais, a pesquisa revela a importância da elaboração de um índice de Segregação Socioespacial como ferramenta de gestão e análise do espaço urbano, uma vez que permitiu, através da síntese dos indicadores, revelar o estado do fenômeno analisado. Ou seja, através dos resultados, foi possível identificar o nível de segregação socioespacial da cidade e categorizar quais regiões são mais afetadas por esse processo.

Para tanto, tornou-se indispensável um esforço teórico para identificação, através da literatura sobre a temática, das categorias que explicam a situação do fenômeno da segregação socioespacial. Identificou-se então, por meio dessa literatura, três categorias explicativas, são elas: Separação Espacial, Separação Social e Desigualdades de Acessos. Cada qual composta por variáveis explicativas, que juntas, após utilização da fórmula matemática elaborada, possibilitaram ilustrar a configuração do fenômeno da segregação socioespacial na cidade de Viçosa, MG.

Com o desenvolvimento do índice, foi possível gerar resultados e análises que auxiliem no planejamento urbano de Viçosa, MG, uma vez que isso possibilitou revelar as regiões urbanas de planejamento com os maiores índices de segregação socioespacial e consequentemente de maiores necessidades de direcionamento de recursos e políticas públicas, ou seja, revela as regiões que precisam de prioridades em termos de intervenções do poder público e maior atenção do Estado, seja construindo escolas, implantando PSF's, infraestrutura, maior segurança, bem como proporcionando a essas pessoas melhor acessibilidade às áreas de trabalho e consumo.

Em suma, tais resultados abrem caminhos para novas pesquisas, principalmente no que se refere ao aprofundamento tanto do processo histórico de segregação socioespacial da cidade de Viçosa, MG, quanto do entendimento e análise das realidades cotidianas das regiões urbanas de planejamento com os piores índices de segregação socioespacial. Em outras palavras, torna-se interessante entender o processo de urbanização da cidade de Viçosa, MG, e como isso afetou, ao longo dos anos, no processo de criação de regiões com altos índices de segregação socioespacial.

\section{REFERÊNCIAS}

ALONSO, William. Location and land use. Cambridge, Mass.: Harvard University Press, 1965.

ANSELIN, Luc. Local indicator of spatial association - LISA. Geografical Analysis, v. 27, n. 2, p. 91-115, abr. 1995.

BONDUKI, Nabil; ROLNIK, Raquel. Periferia da Grande São Paulo: reprodução do espaço como expediente de reprodução da força de trabalho. In: MARICATO, E. (Org.). A produção capitalista da casa (e da cidade) do Brasil industrial. São Paulo: Alfa-Ômega, 1982. p. 117-54.

BONDUKI, Nabil. Uma cidade aberta e segura. 2010. Disponível em: http://www.cartacapital.com.br/ sociedade/uma-cidade-aberta-e-segura . Acesso em: 31 mar. 2017.

BONDUKI, Nabil. Origens da habitação social no Brasil. Aquitetura moderna, lei do inquilinato e difusão da casa própria. 3. ed. São Paulo: Estação Liberdade/FAPESP, 1998.

BRASIL. Ministério do Desenvolvimento Social e Combate à Fome. Secretaria Nacional de Assistência Social. Sistema único de Assistência Social (SUAS). Norma Operacional Básica NOB/SUAS: construindo as bases para a implantação do Sistema Único de Assistência Social, 2005. Disponível em: http://www. assistenciasocial.al.gov.br/sala-de-imprensa/arquivos/NOB-SUAS.pdf. Acesso em: 31 mar. 2017 
CALDEIRA, Teresa Pires do Rio. Cidade de muros: crime, segregação e cidadania em São Paulo. São Paulo: Editora 34/Edusp, 2000. 400p.

CALDEIRA, Teresa Pires do Rio. Enclaves fortificados: a nova segregação urbana. Novos Estudos CEBRAP, São Paulo, n. 47, p. 155-76, mar. 1997.

CASTELLS, Manuel. A questão urbana. Rio de Janeiro: Paz e Terra, 1983.

COELHO, Dayana Debossan. Da fazenda ao bairro: a construção de uma nova Viçosa (1970-2000). 2013. Orientadora: Maria Isabel de Jesus Chrysostomo. Monografia (Bacharelado em Geografia) - Universidade Federal de Viçosa, Viçosa, MG, 2013.

CORRÊA, Roberto Lobato. O Espaço Urbano. São Paulo: Ática, 1989.

CRUZ, Tancredo Almada. Retrato social de Viçosa V. Viçosa, MG: CENSUS, 2014. Disponível em: http:// docplayer.com.br/7597147-Retrato-social-de-vicosa.html. Acesso em: 3 mar. 2017

DA SILVA, Ananias Ribeiro et al. Retrato Social de Viçosa III. Viçosa, MG: CENSUS, 2010.

DO LAGO, Luciana Corrêa. A lógica segregadora na metrópole brasileira: novas teses sobre antigos processos. In: ACSELRAD, Henri (Ed.). Planejamento e território: ensaios sobre a desigualdade. Rio de Janeiro: Lamparina/IPPUR, 2002. p. 155-76.

GUIMARÃES, Maria Clariça Ribeiro. Os movimentos sociais e a luta pelo direito à cidade no Brasil contemporâneo. Serviço Social \& Sociedade, São Paulo, n. 124, p. 721-45, out./dez. 2015.

HUGHES, Pedro Javier Aguerre. Segregação socioespacial e violência na cidade de São Paulo: referências para a formulação de políticas públicas. São Paulo em Perspectiva, São Paulo, v. 18, n. 4, p. 93-102, out./ dez. 2004.

IBGE-CIDADES. 2015. Disponível em: http://cidades.ibge.gov.br/xtras/perfil.php?lang=\&codmun=3171 30\&search=minas-gerais|vicosa. Acesso em: 31 mar. 2017.

LEFEBVRE, Henri. A revolução urbana. Tradução de Sérgio Martins. Belo Horizonte: Editora da UFMG, 2002.

LOJKINE, Jean. O estado capitalista e a questão urbana. São Paulo: Martins Fontes, 1981.

MARICATO, Ermínia. Ciclo de debates. 2013. Disponível em: https://fpabramo.org.br/2013/09/24/erminiamaricato-e-a-convidada-do-ciclo-classes-sociais/ Acesso em: 3 maio 2016.

MARICATO, Ermínia. Urbanismo na periferia do mundo globalizado: metrópoles brasileiras. São Paulo em Perspectiva, São Paulo, v. 14, n. 4, p. 21-33, out./dez. 2000.

MARICATO, Ermínia. Habitação e cidade. São Paulo: Atual, 1997.

OBSERVATÓRIO REGIONAL BASE DE INDICADORES DE SUSTENTABILIDADE (ORBIS). Serviço Social da Indústria. Departamento Regional do Estado do Paraná. Construção e análise de indicadores. Curitiba: [s.n.], 2010.

PINCON-CHARLOT, Monique; PRETECEILLE, Edmond; RENDU, Paul. Ségrégation urbaine. Classes sociales et équipements collectifs en Région parisienne, Paris: Arthropos, 1986.

SOUZA, Nilo Sérgio. As sociabilidades possiveis em conjuntos habitacionais do Programa Minha Casa, 
Minha Vida (PMCMV): o caso de Viçosa - MG. 2015. 150f. Dissertação (Mestrado em Economia Doméstica) - Universidade Federal de Viçosa, Viçosa, MG, 2015.

SPOSITO, Maria Encarnação Beltrão. Segregação socioespacial e centralidade urbana. In: PINTALDI, Silvana Maria; VASCONCELOS, Pedro Almeida; CORREA, Roberto Lobato (Org.). A cidade contemporânea: segregação espacial. São Paulo: Contexto, 2016. p. 61-93.

VETTER, David; MASSENA, Rosa Maria. Quem se apropria dos benefícios líquidos dos investimentos do Estado em infra-estrutura? Uma teoria de causação circular. In: MACHADO DA SILVA, L. A. (Org.). Solo urbano: tópicos sobre o uso da terra. Rio de Janeiro: Zahar, 1981. p. 49-77.

VILLAÇA, F. Espaço intra-urbano no Brasil. São Paulo: Studio Nobel/FAPESP, 2001.

VILLAÇA, Flávio. São Paulo: segregação urbana e desigualdade. Estudos Avançados, São Paulo, v. 25, n. 71, p. 37-58, jan./abr. 2011.

\section{Sobre os autores:}

Reinaldo Antônio Bastos Filho - Doutorando em Economia Doméstica, Mestre em Administração, Especialista em Gestão da Produção e Bacharel em Gestão de Cooperativas, todos pela Universidade Federal de Viçosa (UFV). Bacharel em Administração Pública pela Universidade Federal de Ouro Preto (UFOP). E-mail: reinaldinhogestorufv@hotmail.com, Orcid: http://orcid. org/0000-0002-8790-6117

Neide Maria de Almeida Pinto - Pós-Doutorado em Sociologia no Centro de Investigação em Ciências Sociais da Universidade do Minho em Portugal (2013). Doutorado em Ciências Sociais pela Pontifícia Universidade Católica de São Paulo (PUC-SP). Estágio de doutorado sanduiche junto ao Centre National de la Recherche Scientifique- Observatoire Sociologique du Changement sob orientação do prof. Serge Paugam, em Paris, França. Mestrado e graduação em Economia Doméstica pela Universidade Federal de Viçosa (UFV). Professora associada, vinculada ao Departamento de Economia Doméstica na UFV. Coordenadora do Programa de Pós-Graduação em Economia Doméstica e Presidente da Comissão de Pesquisa e de Ensino do DED. E-mail: nalmeidapinto@gmail.com, Orcid: http://orcid.org/0000-0002-8713-5471

Ana Louise de Carvalho Fiúza - Pós-Doutorado no Centro de Investigações em Ciências Sociais da Universidade do Minho, em Portugal, na linha de pesquisa "População, Família e Saúde". Doutorado em Ciências Sociais em Desenvolvimento, Agricultura e Sociedade na Universidade Federal Rural do Rio de Janeiro (UFRRJ). Mestrado em Extensão Rural pela Universidade Federal de Viçosa (UFV). Especialização em Ciências da Religião e graduação em Ciências Sociais na Universidade Federal de Juiz de Fora (UFJF). Professora Associada III do Departamento de Economia Rural da UFV. E-mail: louisefiuza@gmail.com, Orcid: http://orcid.org/0000-0003-1720-9559

Dimitri Fazito de Almeida Rezende - Estágio pós-doutoral na University of Florida (EUA), pesquisando a aplicação da Análise de Redes Sociais em Demografia. Doutorado em Demografia, mestrado em Sociologia e graduação em Ciências Sociais pela Universidade Federal de Minas Gerais (UFMG). Professor adjunto (Dedicação Exclusiva) do Departamento de Sociologia, UFMG. Integrante e atual Coordenador do Grupo Interdisciplinar de Pesquisa em Análise de Redes Sociais (GIARS), FAFICH/UFMG. E-mail: dfazito@gmail.com, Orcid: http://orcid.org/0000-0003-1720-9559 
